\title{
RESEARCH ON OPTIMIZATION OF HULL LINES FOR MINIMUM RESISTANCE BASED ON RANKINE SOURCE METHOD
}

Bao-Ji Zhang

College of Ocean Environment Engineering, Shanghai Maritime University, Shanghai 201306, China., zbj1979@163.com

Follow this and additional works at: https://jmstt.ntou.edu.tw/journal

Part of the Environmental Engineering Commons

\section{Recommended Citation}

Zhang, Bao-Ji (2012) "RESEARCH ON OPTIMIZATION OF HULL LINES FOR MINIMUM RESISTANCE BASED ON RANKINE SOURCE METHOD," Journal of Marine Science and Technology. Vol. 20: Iss. 1, Article 11.

DOI: $10.51400 / 2709-6998.2426$

Available at: https://jmstt.ntou.edu.tw/journal/vol20/iss1/11

This Research Article is brought to you for free and open access by Journal of Marine Science and Technology. It has been accepted for inclusion in Journal of Marine Science and Technology by an authorized editor of Journal of Marine Science and Technology. 


\section{RESEARCH ON OPTIMIZATION OF HULL LINES FOR MINIMUM RESISTANCE}

BASED ON RANKINE SOURCE METHOD

Acknowledgements

Foundation item: the National Natural Science Foundation of China (No. 51009087). 


\section{RESEARCH ON OPTIMIZATION OF HULL LINES FOR MINIMUM RESISTANCE BASED ON RANKINE SOURCE METHOD}

\begin{abstract}
Key words: rankine source method, SGA, NGA, NLP, optimization design.

ABSTRACT

In order to obtain the hull form with the excellent resistance performance, the optimal design program of hull lines with the independent intellectual property is developed. An optimal design method is proposed based on the minimum total resistance and on NGA, SGA and NLP. The fore-body is optimized with total resistance as the objective function, (in which total resistance can be expressed as sum of wave resistance and friction resistance), with the parameter of hull form modification function as design variables, with an appropriate displacement as a constraint. At last, the numerical optimization examples for $\mathrm{s} 60$ ships are provided, which indicates that the resistance is reduced distinctly and the lines is smoothing. We can conclude that the hull optimization based on the Rankine source method is more reliable.
\end{abstract}

Bao-Ji Zhang

\section{INTRODUCTION}

In the process of ships, the determination of hull lines is complicated and pivotal, in respect that ships main performance of the rapidity (resistance and propelling), maneuverability and seakeeping would be influenced directly. However to obtain the hull shape of the minimum resistance is the primary goal of designers. Formerly, the hull lines design which refers excellent original hull is finished by compositive method of the deviser's experience and ship model testing. However, such method requires a great amount of time and labor and also suffers from some limitations. Along the gradual progress of computational fluid dynamics (CFD) and the fast development of the computer technology, the optimization design of the hull lines based on the CFD theory is become feasible. The research result is applied in hull design for the advanced nations with the shipbuilding technology, such as

Paper submitted 04/16/10; revised 10/26/10; accepted 12/23/10. Author for correspondence: Bao-Ji Zhang (e-mail: zbj1979@163.com).

College of Ocean Environment Engineering, Shanghai Maritime University, Shanghai 201306, China.
Europe, America, Japan , Korea ,etc. But, at present, the traditional and experiential method is used in ships design department in our country [8]. Nowadays, the shipbuilding capacity of our country is in the front of world, however the shipbuilding technology is unenlightened slightly. In order to increase competitiveness and cability of ship form development in international market, an optimization design method of excellent hull lines with the resistance performance and to development of program of ship lines of optimal design with the independent intellectual property is in urgent need.

In China, the studies on optimization design of hull form with mathematical techniques based on CFD theory started in the 1980s [4], in the world, the initial research was carried out in Japan, the method of the mathematical programming applied to create hull form started in the 1960s. Every country has invested a great effort after the 1980s and with a series of results comed out $[5,1]$. In the study, the NLP has been used as optimization method, the fore-body of hull has been used as design object, and Michell integral method was often used in the calculation of wave making resistance for its fast calculation speed, but has not been put into wide applications due to the large deviation between the calculation results and experimental results. In the 1990 s, the nonlinear wave-making resistance theory was developed. Japanese scholar optimizes hull from by Rankine source method. The actual hull form of the minimum wave-making resistance is obtained by calculation and optimization design of the wave-making resistance based on the Rankine source method [6,7]. In this paper, an optimization design model of minimum wave-making resistance is proposed based on Rankine source method, which combined with NGA, SGA and LNP to take excellent hull lines of the resistance performance rapidly, and also the optimal design program of ship lines with the independent intellectual property is developed.

\section{ESTABLISHMENT OF THE HULL FORM OPTIMIZATION MODEL}

\section{Objective Function}

In the present study, the total resistance $R_{T}$ is selected as objective function in the optimization design process, the $R_{T}$ is expressed the sum of wave making resistance $R_{W}$ and 


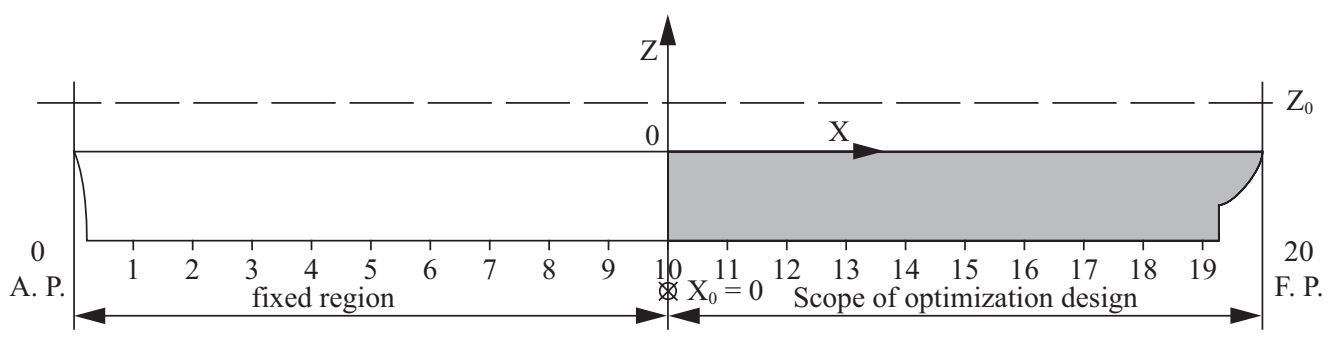

Fig. 1. The scope of optimization design of the S60 hull form.

viscous resistance $(1+\mathrm{K}) R_{\mathrm{F}}$, namely

$$
R_{T}=P \cdot R_{\mathrm{w}}+(K+1) \cdot R_{F} \rightarrow \min
$$

The $R_{W}$ is calculated by the Rankine source method $[9,10]$, the form factor $K$ is calculated by following formula.

$$
K=0.11+0.128 \frac{B}{d}-0.0157\left(\frac{B}{d}\right)^{2}-3.10 \frac{C_{B}}{L / B}+28.8\left(\frac{C_{B}}{L / B}\right)^{2}
$$

where $L$ is the ship length between perpendiculars, $B$ is the breadth, $d$ is the draft, $C_{B}$ is the block coefficient and the correction coefficient of wave making resistance $P$ can be taken as a ratio, which is calculated by dividing the experiment value into the theoretical computation value at the design speed of original hull.

$$
R_{F}=\frac{1}{2} \cdot \rho \cdot U_{\infty}^{2} \cdot S^{2} \cdot C_{f 0}
$$

$C_{f 0}$ is the frictional resistance coefficient of a flat plate.

$$
\begin{gathered}
C_{f 0}=0.463\left(\log _{10} R \mathrm{e}\right)^{(-2.6)} \\
R_{e}=\frac{U_{\infty} L}{v}
\end{gathered}
$$

where $U_{\infty}$ is the design speed, $\rho$ the density of the fluid, $S$ the wetted hull surface area, $R_{e}$ the Reynolds number and $v$ the coefficient of kinematic viscosity for fluid.

\section{Design Variables and Hull Form Modification Function}

The fore half of the hull form is selected as the scope of optimization design, moreover, hull bottom, water plan, stem and stern profiles cannot be modified in hull form improvement, as shown in Fig. 1.

In the optimization process, the hull form modification function $w(x, z)$ is introduced to represent an improved hull surface $y(x, z)$ [6], which can be used to generate a new hull surface by multiplying it by the offset data of the original hull surface $f_{0}(x, z)$, namely.

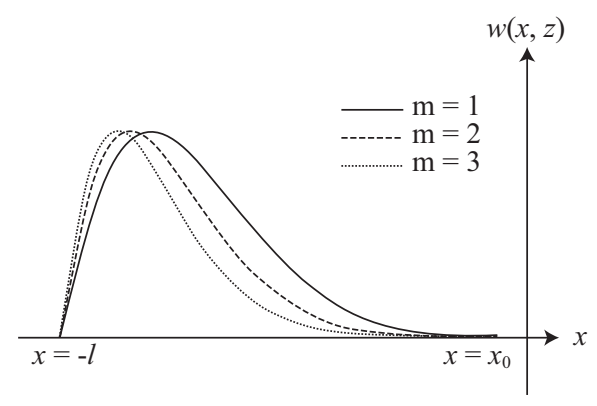

Fig. 2. The basic weight function.

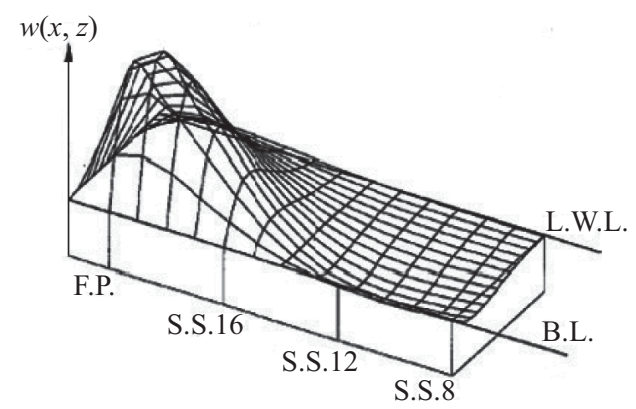

Fig. 3. The shape of the hull form modification function.

$$
y(x, z)=f_{0}(x, z) \cdot w(x, z)
$$

$w(x, z)=1-\sum_{m} \sum_{n} A_{m n} \sin \left[\pi\left(\frac{x-x_{0}}{x_{\max }-x_{0}}\right)^{m+2}\right] \cdot \sin \left[\pi\left(\frac{z_{0}-z}{z_{0}+d}\right)^{n+2}\right]$

$(m, n=1,2,3 \ldots \ldots) 0 \leq x \leq \frac{L}{2}, w(x, z)>0,\left(x<x_{0}, z<z_{0}\right)$

where $x_{0}$ and $x_{\max }$ are the characteristic parameters for the hull form modification, $L / 2$ is the longitudinal length of the front of the fore body (including the bow bulbs). $d$ is generally the greatest depth which might be modified. If the baseline is unchanged, then $d$ is the draft, and $A_{m n}$ and $z_{0}$ are taken as the design variables in the optimization procedure. Fix $m, n=1$, 2, 3 we will have altogether 9 variables for $A_{m n}$, with total number of design variables not surpassing 10 .

When $(m, n=1,2,3 \ldots \ldots)$, the shape of basic weight function as shown in Fig. 2 and the hull form modification function as shown in Fig. 3. 
Table 1. The optimization results based on the NGA, SGA and NLP.

\begin{tabular}{cccccccc}
\hline Optimization method & Constraint conditions & Design $F n$ & $R_{W} / R_{W 0}$ & $R_{F} / R_{F 0}$ & $R_{T} / R_{T 0}$ & $V / V_{0}$ & $S / S_{0}$ \\
\hline NGA & (1) - (2) & 0.285 & 0.688 & 1.007 & 0.886 & 1.017 & 1.012 \\
SGA & (1) ( (2) & 0.285 & 0.756 & 1.001 & 0.920 & 1.002 & 1.001 \\
NLP & (1) - (2) & 0.285 & 0.812 & 1.004 & 0.945 & 1.039 & 1.011 \\
\hline
\end{tabular}

\section{Constraint Conditions}

The ship's hull was subjected to the following geometric constraints.

(1) The $y$ coordinates of the ship's hull are nonnegative, namely.

$$
y(i, j) \geq 0
$$

(2) The displacement volume must be greater than the original value, namely.

$$
V \geq V_{0}
$$

where $V_{0}, V$ are the displacement volumes of the original hull and the improved hull, respectively.

\section{Optimization Method}

In general engineering optimization problems, the objective functions are nonlinear with respect to the design variables, and complex design constraints are imposed. In this paper, the SUMT of the NLP, SGA [2] and NGA [3] are selected to minimize the objective function under design constraints.

\section{An Example of Hull Form Optimization}

In this article, the $\mathrm{S} 60$ hull form is selected as the original hull to be optimized. The hull surface is divided into 100 panes. The free surface is divided into 704 panes and the free surface domain is taken from 1.5 ship length upstream to 2.5 ship length downstream and its transverse extension is about 1.5 ship length. The principal particulars and hull grid are shown in document [8].

The optimization results show that while $F n=0.285$, the total resistance and wave-making resistance are decreased rapidly by three optimization methods, especially the NGA, as shown in Table 1.

The comparisons of body plans between the optimized hull form (NGA, SGA and NLP) and the original hull are shown in Figs. 4, 5 and 6 . The resulting forms are entirely dictated by the hydrodynamic behavior associated with the changes in hull shape, and the optimized hull form (NGA, SGA and NLP) has scarcely deviated from the original hull, and the frame lines of the fore-body of hull become U-shaped for the modified hull, and this effectively makes the water plane narrower and moves the volume from the upper to the lower region. Among them, the optimal hull form from the method of NGA makes the offset more obvious.

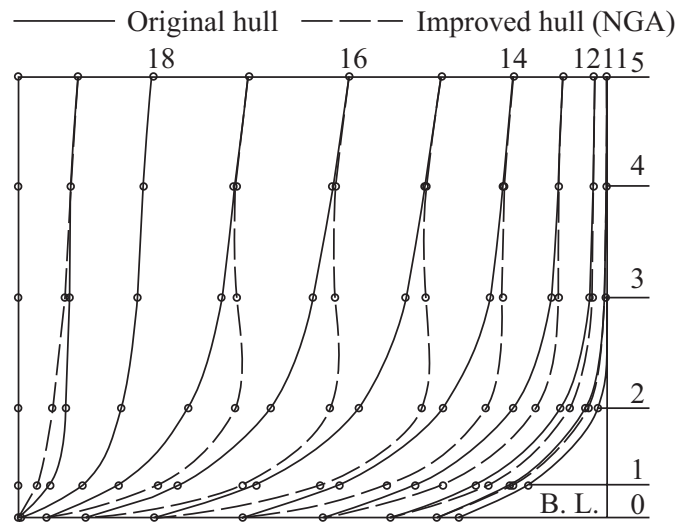

Fig. 4. The comparison of body plans between the original hull form and the improved hull form (NGA).

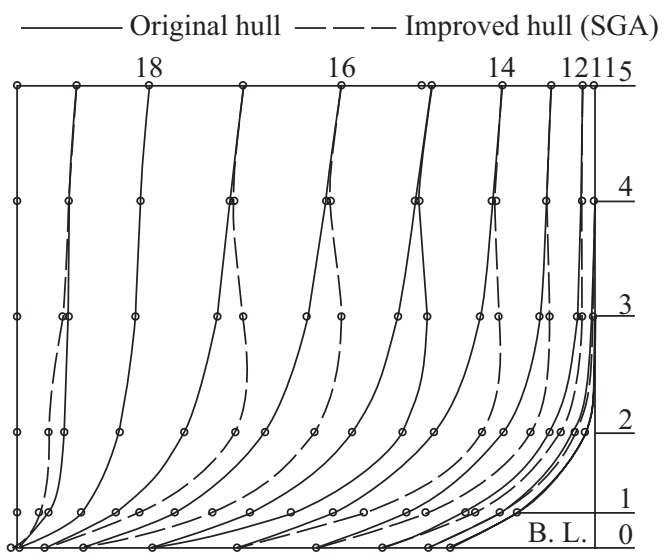

Fig. 5. The comparison of body plans between the original hull form and the improved hull form (SGA).

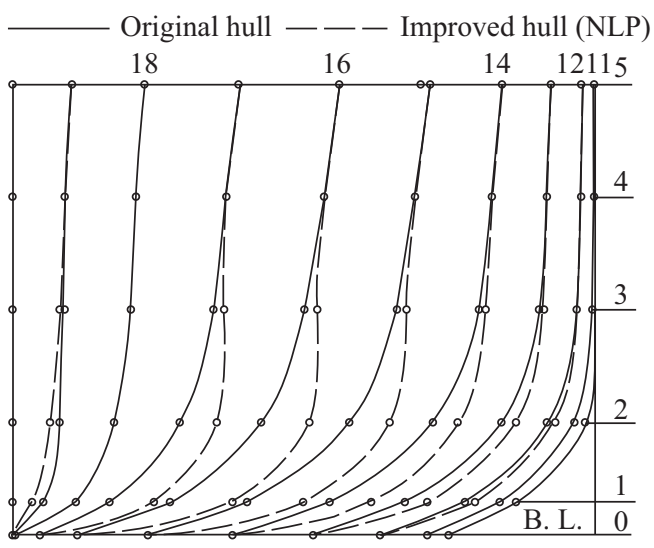

Fig. 6. The comparison of body plans between the original hull form and the improved hull form (NLP). 


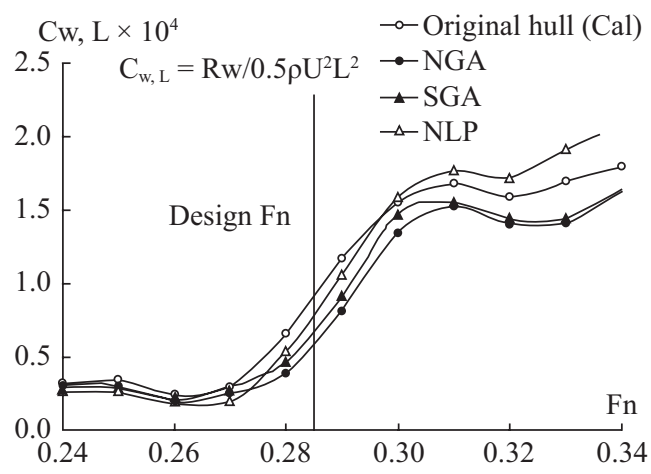

Fig. 7. The comparison of wave making resistance coefficient curves between the original hull form and the improved hull form.

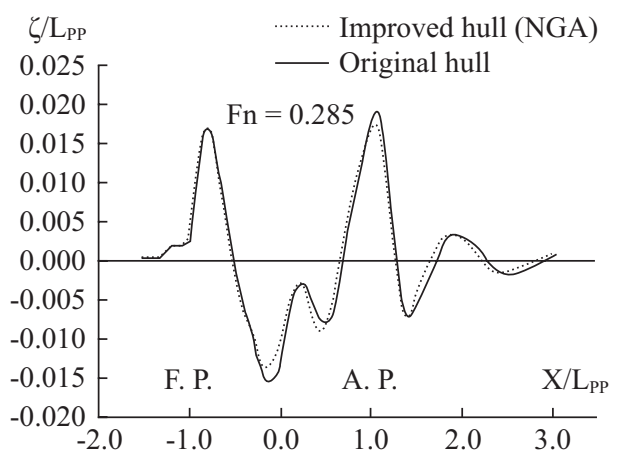

Fig. 8. The waveform along the hull of the original hull form of and the improved hull form (NGA).

Fig. 7 shows the comparisons of the wave making resistance coefficient for the improved hull and the original hull. It can be seen that a reduction in the wave making resistance coefficient is achieved. The optimized forms lead to a less wave making resistance over a wide range of design speeds.

The comparisons through the calculated wave profiles along the hull are shown in Figs. 8, 9 and 10, respectively. The optimized hull generates a slightly greater wave height at the bow than the original hull. This is due to the increased steepness of the waves created at the bowl. This phenomena is likely to have be caused by the following reasons:

(1) The wave profiles use free surface's wave height of hull accessory, not in the actual hull, especially in the stem and bow.

(2) Free surface based on linearization can not be simulated actual boundary condition completely, because the stem and bow of ship are affected by the intense nonlinear.

Figs. 11, 12 and 13 show the contours of the non-dimensional wave pattern calculated for the optimized hull (lower) and the corresponding wave patterns for the original hull (upper) at $F n=0.285$ respectively. From the diagram, we can find that optimal hull form has obvious shape of Kelvin Waves. The differences in the wave fields generated by optimized hulls and the original hull are clear.

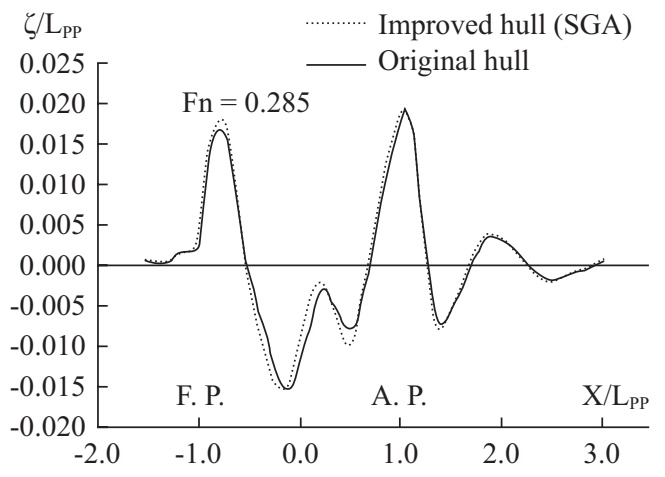

Fig. 9. The waveform along the hull of the original hull form of and the improved hull form (SGA).

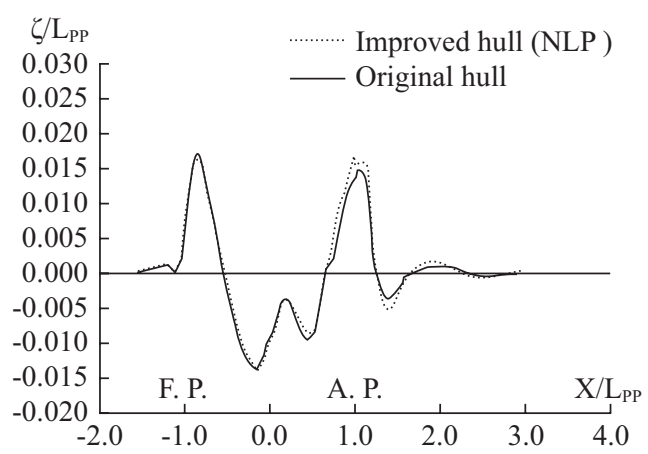

Fig. 10. The waveform along the hull of the original hull form of and the improved hull form (NLP).

\section{THE COMPARISONS OF THE OPTIMIZATION RESULT BETWEEN GA AND LNP}

The comparisons of the resistance performance and waste time of the optimal hull (NGA, SGA and NLP) are shown in Figs. 14 and 15, respectively. The resistance performance of the optimal hull (NGA and SGA) is better than NLP, and the hull lines of the improved hull shift to side more obviously, in addition, the small bow bulb is obtained in optimization process. At least, from this point of view, the NGA and SGA are more excellent than traditional optimization method. But, the optimization speed is quite slower than NLP. So, how to increase the calculating speed of optimization (NGA and SGA) will be discussed in later research.

\section{CONCLUSION}

In the present studies, NGA, SGA and NLP have been introduced to optimize the hull lines. In the optimization process, the minimum total resistance is taken as objective function, the parameters of hull form modification function are used as the design variables, and the displacement is used as the constraint to optimize the bow-body of hull.

Three improved hulls are obtained by the optimization of the bow-body of the hull with S60 hull form as the original 


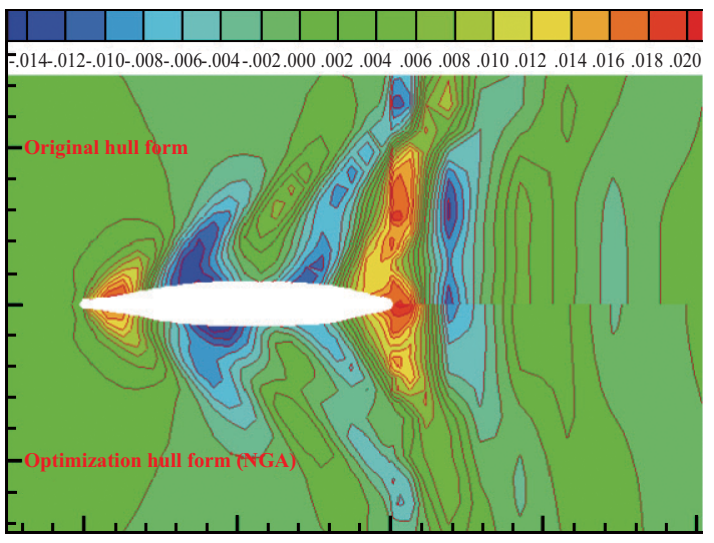

Fig. 11. The waveform contours of the original hull form and the improved hull form (NGA).

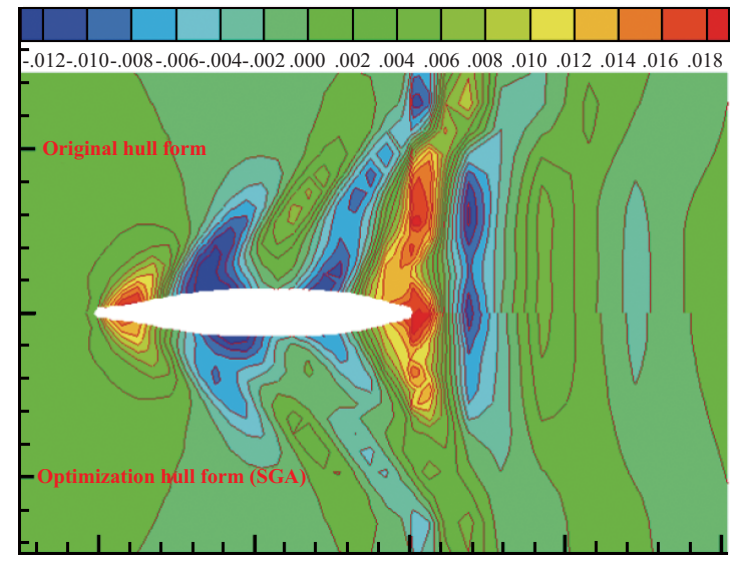

Fig. 12. The waveform contours of the original hull form and the improved hull form (SGA).

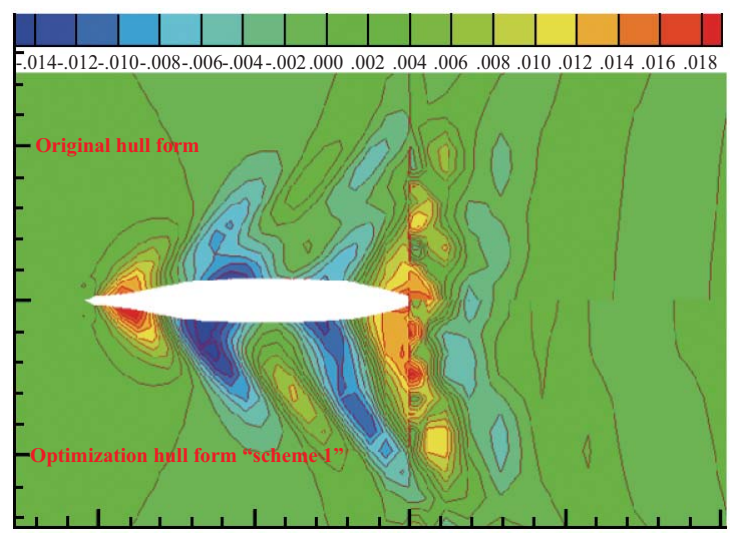

Fig. 13. The waveform contours of the original hull form and the improved hull form (NLP).

hull. Then we get the optimum hull form under the condition that the design speed $F n$ is 0.285 . Total resistance and wavemaking resistance are reduced by about $11.4 \%$ and $31.2 \%$ for NGA, $8.0 \%$ and $24.4 \%$ for SGA, and $5.5 \%$ and $18.8 \%$ for

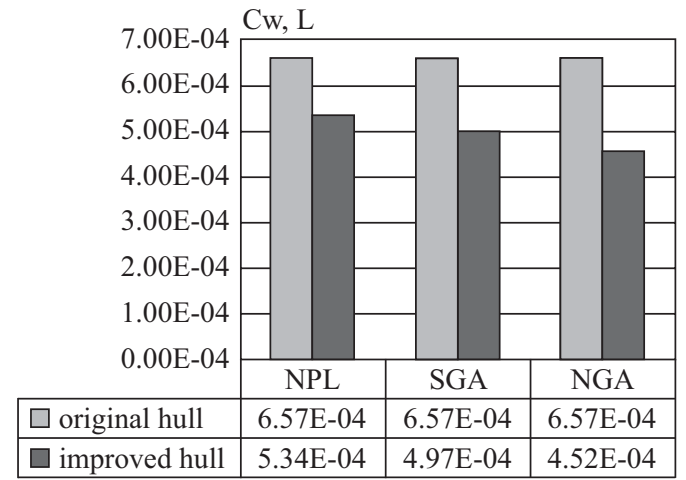

Fig. 14. The comparison of the reduced resistance effect of the GA and NLP.

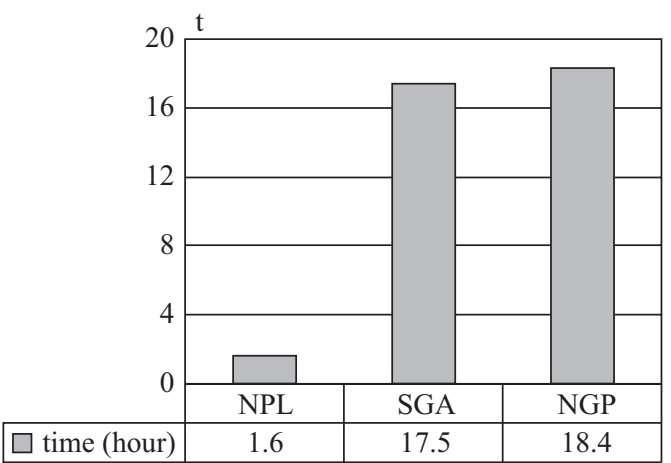

Fig. 15. The comparison of the expensed time of the GA and NLP.

NLP, respectively compared with initial hull form. Furthermore, the improved hull is smooth and more close to the actual hull. Therefore, We can get conclusion that NGA method performs better in optimization calculation by the comparison of the optimal results to SGA and NLP.

\section{ACKNOWLDEGMENTS}

Foundation item: the National Natural Science Foundation of China (No. 51009087).

\section{REFERENCES}

1. Hamasaki, J. and Himeno, Y., "Hull form optimization by nonlinear programming (part1) -Improvement of prismatic curve for minimizing wave resistance," Journal of the Kansai Society of Naval Architects of Japan, No. 223, pp. 29-34 (1995)

2. Ling, Q., Wu, G., Yang, Z., and Wang, Q., "Crowding clustering genetic algorithm for multimodal function optimization," Applied Soft Computing, Vol. 8, pp. 88-95 (2008).

3. Liu, J.-H. and Yan, D.-K., "Niche genetic algorithm with accurate optimization performance," China University of Mining \& Technology (English Edition), Vol. 15, No. 2, pp. 100-104 (2005).

4. Ma, K. and Ichiro, T., "A study of optimal hull from for minimum resistance," Journal of Hydrodynamics, Ser. A, Vol. 12, No. 1, pp. 113-122 (1997).

5. Suzuki, K., Ikehata, M., and Iiiguchi, M., "Fundamental studies on ship hull form design by means of nonlinear programming (2nd report)- 
Application of low speed theory \& experimental verification," Journal of the Kansai Society of Naval Architects of Japan, No. 155, pp. 49-55 (1981).

6. Suzuki, K. and Iokamori, N., "Studies on minimization of wave making resistance based on rankine source method," Journal of the Kansai Society of Naval Architects of Japan, No. 185, pp. 9-19 (1999).

7. Suzuki, K., Kai, H., and Kashiwabara, S., "Studies on the optimization of stern hull form based on a potential flow solver," Journal of Marine Science and Technology, Vol. 10, No. 2, pp. 61-69 (2005).
8. Zhang, B.-J., "Research on optimization design of hull Lines and minimum resistance hull form," Ph.D. Thesis, Dalian University of Technology, Dalian, China (2009).

9. Zhang, B.-J., Ma, K., and Ji, Z.-S., "Numerical calculation research of wave resistance on Rankine source method," Journal of Dalian University of Technology, Vol. 49, No. 6, pp. 872-875 (2009).

10. Zhang, B.-J., Ma, K., and Ji, Z.-S., "The optimization study for hull form of minimum wave making resistance based on Rankine source method," Journal of Hydrodynamics, Ser. B, Vol. 21, No. 2, pp. 277-284 (2009). 